\title{
Malaria Transmission Pattern in an Area Selected for Clinical Trials in the Sudanian Area of Senegal (West Africa)
}

\author{
El Hadji Amadou Niang, ${ }^{1,2}$ Aissatou Touré, ${ }^{3}$ El Hadji Malick Ngom, ${ }^{1,2}$ Lassana Konaté, ${ }^{2}$ \\ Ousmane Faye, ${ }^{2}$ Mawlouth Diallo, ${ }^{1}$ and Ibrahima Dia ${ }^{1}$ \\ ${ }^{1}$ Unité d'Entomologie Médicale, Institut Pasteur de Dakar, BP 220, Dakar, Senegal \\ ${ }^{2}$ Laboratoire d'Ecologie Vectorielle et Parasitaire, Département de Biologie Animale, Faculté des Sciences et Techniques, \\ Université Cheikh Anta Diop de Dakar, BP 5005, Dakar, Senegal \\ ${ }^{3}$ Unité d'Immunologie, Institut Pasteur de Dakar, BP 220, Dakar, Senegal \\ Correspondence should be addressed to Ibrahima Dia; dia@pasteur.sn
}

Received 4 October 2012; Revised 17 December 2012; Accepted 28 December 2012

Academic Editor: Marcel Tanner

Copyright (C) 2013 El Hadji Amadou Niang et al. This is an open access article distributed under the Creative Commons Attribution License, which permits unrestricted use, distribution, and reproduction in any medium, provided the original work is properly cited.

\begin{abstract}
Malaria transmission pattern was studied in 3 villages (Toubanding, Daga Ndoup, and Keur Samba Guèye) situated within an area selected for clinical trials. The study was conducted in the rainy season from July to December 2011. The main objective of this work was to gather baseline data on malaria transmission intensity and other entomological parameters before the advent of clinical trials. Mosquitoes were collected by Human-Landing Collections (HLCs) and by pyrethrum spray catches (PSCs). Five anopheline species were collected, namely, An. arabiensis, An. gambiae, An. funestus, An. pharoensis, and An. rufipes, giving a heterogeneous distribution within the study area. The populations dynamics of the vectors varied temporarily in each village depending on the pattern of the rainy season. Transmission intensity estimated by the entomological inoculation rate (EIR) was measured in each of the three villages with the variations linked to the microecological differences between the villages. Measurements were calculated for August, September, and October and were found to vary between 4 and 30 infected bites per person over the study period with a peak intensity observed in September. These results indicate that epidemiological field trials on malaria could be conducted in this area on the basis of the differences observed with transmission intensity, micro-ecological variations, and the objectives of the trials.
\end{abstract}

\section{Background}

Malaria continues to be a major public health problem throughout the world despite more than a century of study, especially in Africa where $90 \%$ of the global cases are recorded. The situation is worsening due to the spread of drug resistant parasites strains, spread of insecticide resistance in the vector populations, and poor economic status of endemic populations [1]. To alleviate the problem, an integrated approach against both the parasites and vectors for an effective control is necessary.

Over the last five years, considerable efforts have been made to control malaria in many countries around the world (especially in Sub-Saharan Africa) using strategic measures with available tools. This has led to the decline in malaria transmission in many parts of Africa [2, 3]. These changes are as a result of an extensive use of long-lasting insecticidal nets (LLINs) and improved malaria diagnosis and treatment. However, despite these significant progresses, malaria remains an acute problem killing 800000 people each year, mostly children under five years living in Sub-Saharan Africa [1]. The situation is particularly worrying with the increase in poverty for sustainability and more specifically as different models predict a loss of immunity of the populations with the current interventions $[4,5]$. The rebound effect and age shift of malaria morbidity associated with an increasing susceptibility of older children and adults as seen in many places after the introduction of control strategies also help to sustain this hypothesis [6]. Change in behaviour of the vector populations from being endophilic to exophilic also makes 
the populations vulnerable [7]. The need for efficient and effective sustainable strategies including curative treatments and vaccines for malaria control is therefore eminent. The evaluation of such strategies requires detailed information on the epidemiology of malaria and the vector populations. An ideal indicator of malaria risk is the entomological inoculation rate (EIR), a parameter that relates both the behaviour and human-biting activity of the anopheline vectors and the risk to humans of malaria infection. Risk of exposure of human to infectious bites of vectors is not uniform in any geographical setting even within limited distances in an area. The variations in the abundance and dispersal of mosquitoes occur spatially and temporally in a given area and these variations can impact on the level of malaria transmission [8]. Thus, the evaluation of interventions under conditions of natural transmission requires that testing sites should be identified and characterized with baseline information derived before the implementation of the interventions.

Indeed, it is necessary to gather precise information and make a close follow up of variations in malaria transmission in an area identified for interventions to enable correct interpretations of malaria parameters such as parasitaemia, morbidity, and associated immune responses in relation to efficacy [9].

This study was undertaken within the European and Developing Countries Clinical Trials Partnership (EDCTP) framework aimed at characterizing selected study sites for clinical trials in the Sudanian bioclimatic area of Senegal. Temporal and seasonal variations in species composition, density, biting behaviour, and intensity of malaria transmission rates and ecological parameters are the key indicators that have been studied.

\section{Materials and Methods}

2.1. Study Sites. The study was conducted in the rural community of Toubacouta in the Sine Saloum region. Nine villages were identified in the area and 3 (Daga Ndoup, Keur Samba Guèye, and Toubanding) were selected for entomological monitoring from July to December 2011 (Figure 1). The GPS coordinates for each of the 9 villages were recorded and the water network system identified as well as socioecological features like landscape, agricultural practices, access to health facilities, and vector control measures. Epidemiological and demographic data were also collected and parameters include age variations, inclusion rates. The selected villages are situated around the field research stations of Dielmo and Ndiop where extensive research on malaria has previously been conducted $[10,11]$. Nema river passes through Toubanding, whereas the nearest water body (a pool) around Keur Samba Guèye is situated $1 \mathrm{~km}$ away with temporary puddles within the village of Daga Ndoup during the rainy season. The climate is Sudan-type savanna in this region with a rainy season that lasts from June to mid-October. The recorded monthly rainfall derived from Tropical Rainfall Measuring Mission (TRMM) data within the study area was 101, 134, 162, 153, and $118 \mathrm{~mm}$ from July to November 2011, respectively. Farming activities are concentrated mainly on food and cash crops

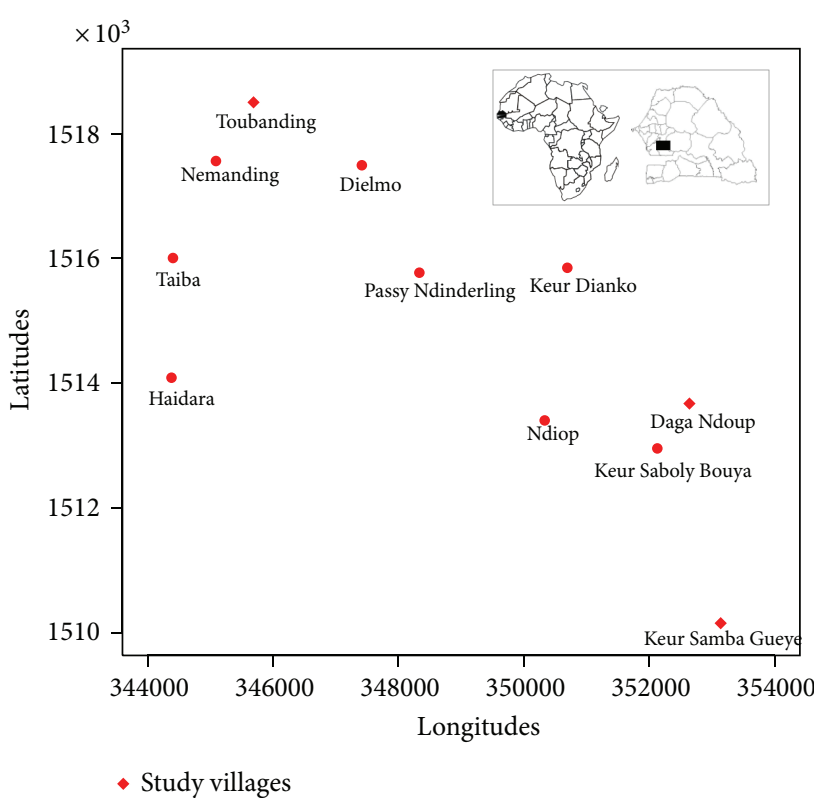

FIGURE 1: Map of the study area showing the three study villages.

(maize, millet, groundnuts, and vegetables). Trade and rearing of domestic animals like cows, sheep, goats, and chicken are also common practices of the people. Houses are of traditional types with mud walls and thatched or corrugated iron roofs. Ethical approval for this study was obtained from the Senegalese National Ethics Committee.

2.2. Mosquito Sampling and Field Processing. Entomological surveys were conducted using two classical methods: all nights Human-Landing Collections (HLCs) from two selected sentinel houses in each village (indoors and outdoors for two consecutive nights each month) and pyrethrum spray collections (PSCs) in 10 randomly selected rooms in each village. After collection, mosquitoes were sorted, counted, and morphologically identified to species [12]. A proportion of unfed females from each species were dissected to extract ovaries and to determine parity by observing the degree of coiling of ovarian tracheoles [13]. The blood meals from freshly fed females collected by PSC were squashed onto Whatman filter paper and dried for host source identification. All the mosquito samples collected were stored individually in numbered vials with desiccant until laboratory processing.

2.3. Laboratory Processing. The origin of blood meals from freshly fed indoor resting females collected after pyrethrum spray collections was identified as human, bovine, ovine, and horse using an Enzyme-Linked Immunosorbent Assay (ELISA) from Beier et al. procedure [14]. The heads and thoraces of all anopheline females were tested by ELISA for the detection of Plasmodium falciparum circumsporozoite protein (CSP) using Wirtz et al. procedure [15]. For each month, a random sample of 30 females belonging to the An. gambiae complex was identified to species and molecular forms levels by the molecular method described by 
Fanello et al. [16]. All CSP positive An. gambiae s.l. mosquitoes were also analysed by the same molecular method.

2.4. Data Analysis. The human-biting rate (HBR) was defined for each species collected as the ratio of the total number collected to the total person-nights for the collection period. The endophagous rate was defined as the proportion of mosquitoes captured indoors against the total of both indoors and outdoors collections from HLC. The circumsporozoite rate was calculated as the proportion of total numbers of mosquitoes collected found to contain the Plasmodium falciparum CS protein. The anthropophilic rate was calculated as the proportion found with human blood out of the total analysed. The entomological inoculation rate (EIR) was calculated as the product of the human-biting rate (HBR) and the CSP rate of mosquitoes collected from night catches. All these parameters were computed and analysed using the free software R-gui version 2.15.1.

\section{Results}

3.1. Anopheline Collections. A total of 468 Anopheles specimens were collected from July to December 2011 by HLC and the composition includes mainly An. gambiae s.l., An. funestus, and An. pharoensis. An. gambiae s.l. was the predominant species in the three villages (Table 1). An. funestus was also collected in the three villages but its abundance was the highest only in Toubanding village (20\%). In Daga Ndoup and Keur Samba Guèye, $1.7 \%$ and $3 \%$ were represented by An. funestus. An. pharoensis was less represented in the collections and was found only in Keur Samba Guèye and Tou-banding villages.

Collections in human dwellings by PSC have yielded 748 anopheline females (Table 1). An. gambiae was found to be the predominant species in all three villages followed by $A n$. funestus collected in Toubanding mainly and to a lesser extent in Daga Ndoup. Although we did not collect An. rufipes by HLC, a good number was collected in Keur Samba Guèye village. An. pharoensis, on the other hand, was not found resting in dwellings in all three villages.

Out of the 468 An. gambiae s.l. females collected by HLC, 168 (37 in Daga Ndoup, 47 in Keur Samba Guèye and 84 in Toubanding) were analysed using the PCR-RFLP. In all 3 villages, An. arabiensis was found to be the predominant species comprising 73\% in Daga Ndoup, 91.5\% in Keur Samba Guèye, and $65.5 \%$ in Toubanding.

3.2. Biting Cycles. The mean number of bites per person per night (bpn) was significantly different for An. gambiae between the three villages $\left(F_{2,33}=15.8, P<0.001\right)$ and for $A n$. funestus $\left(F_{2,33}=4.2, P=0.02\right)$, with the highest biting rates being observed in Toubanding village. For An. pharoensis, no significant difference was observed in biting rates between the 3 villages $\left(F_{2,33}=2.9, P=0.07\right)$

In each of the three villages, the HBR peaked in September for An. gambiae (Figure 2). An. funestus females were collected only in Toubanding village throughout the study period with the highest density observed in December

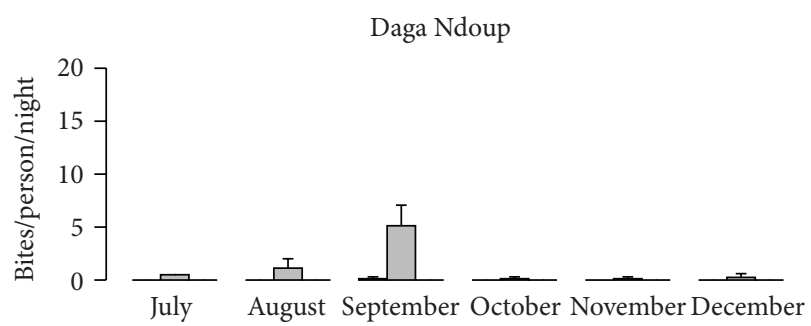

(a)

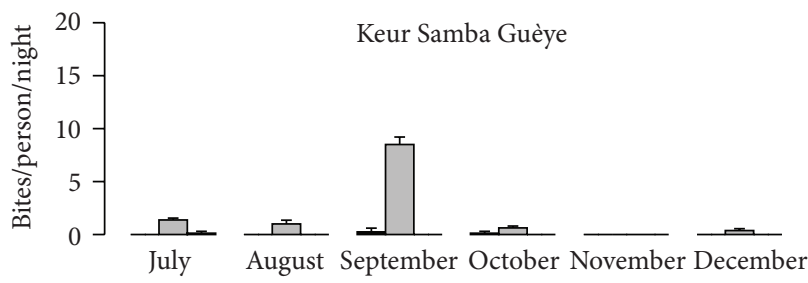

(b)

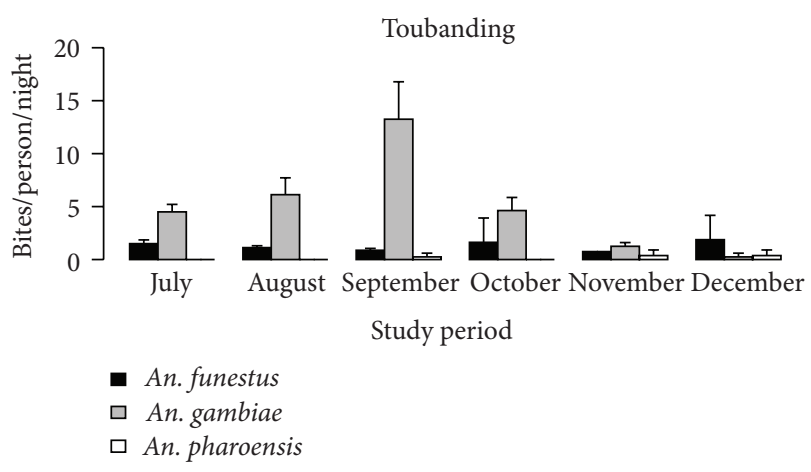

(c)

Figure 2: Temporal dynamics of An. gambiae, An. funestus, and An. pharoensis in Toubanding, Keur Samba Guèye and Daga Ndoup villages from July to December 2011.

(Figure 2). For Daga Ndoup, this species was only present in September (0.12 bpn) and in September (0.25) and October (0.12 bpn) for Keur Samba Guèye village.

The biting rates for $A n$. pharoensis females were generally very low with Keur Samba Guèye recording 0.12 bpn for July only and Toubanding, $0.25 \mathrm{bpn}$ for September, and $0.37 \mathrm{bpn}$ for both November and December.

3.3. Host-Seeking Behaviour. Overall, in Toubanding village, $27.4 \%$ of An. funestus and $47.9 \%$ of An. gambiae captured by HLC were collected indoors. These proportions were significantly different $\left(\chi^{2}=7.6, \mathrm{df}=1\right.$, and $\left.P=0.006\right)$. The proportions of total An. gambiae collected by HLC indoors were not significantly different between the three villages, $\left(\chi^{2}=1.9, \mathrm{df}=2\right.$, and $P=0.38$ ). One female An. funestus was collected outdoors in Daga Ndoup and 1 female An. pharoensis indoors in Keur Samba Guèye.

A total of 413 blood meals from blood fed females from indoor resting mosquitoes (385 An. gambiae and 28 An. funestus) were collected by PSC and tested by ELISA (Table 2). The proportion of human blood meals was $62.6 \%$ in Daga 
TABLE 1: Number of anopheline species collected by HLC and PSC in Daga Ndoup, Keur Samba Guèye, and Toubanding from July to December 2011.

\begin{tabular}{lccccccccccc}
\hline & \multicolumn{3}{c}{$\begin{array}{c}\text { Daga Ndoup } \\
\text { Mosquito species }\end{array}$} & \multicolumn{2}{c}{ HLC } & \multicolumn{3}{c}{ Keur Samba Guèye } & \multicolumn{3}{c}{ Toubanding } \\
& In & Out & In & In & Out & In & In & Out & PSC & Total \\
An. funestus & 0 & 1 & 2 & 3 & 0 & 0 & 17 & 45 & 54 & 122 \\
An. gambiae & 22 & 36 & 403 & 45 & 50 & 118 & 115 & 125 & 170 & 1084 \\
An. pharoensis & 0 & 0 & 0 & 1 & 0 & 0 & 6 & 2 & 0 \\
An. rufipes & 0 & 0 & 0 & 0 & 0 & 1 & 0 & 0 & 0 \\
\hline Total & 22 & 37 & 405 & 49 & 50 & 119 & 138 & 172 & 224 & 1216 \\
\hline
\end{tabular}

TABle 2: Proportions of An. gambiae and An. funestus fed on each vertebrate host in Daga Ndoup, Keur Samba Guèye, and Toubanding among resting mosquitoes.

\begin{tabular}{|c|c|c|c|c|c|c|c|}
\hline \multirow{2}{*}{ Species } & \multirow{2}{*}{ Villages } & \multirow{2}{*}{$\begin{array}{l}\text { Number } \\
\text { identified }\end{array}$} & \multicolumn{4}{|c|}{ Vertebrate hosts (\%) } & \multirow{2}{*}{ Mixed } \\
\hline & & & Human & Bovine & Ovine & Equine & \\
\hline \multirow{3}{*}{ An. gambiae } & Daga Ndoup & 212 & $\begin{array}{c}62.6 \\
{[55.6-69.1]}\end{array}$ & $\begin{array}{c}27.2 \\
{[21.4-33.8]}\end{array}$ & $\begin{array}{l}0 \\
-\end{array}$ & $\begin{array}{c}10.3 \\
{[6.7-15.3]}\end{array}$ & $\begin{array}{c}8 \\
{[5.1-12.5]}\end{array}$ \\
\hline & Keur Samba Guèye & 72 & $\begin{array}{c}65.2 \\
{[53.1-75.5]}\end{array}$ & $\begin{array}{c}31.8 \\
{[21.8-43.8]}\end{array}$ & $\begin{array}{c}0 \\
-\end{array}$ & $\begin{array}{c}3 \\
{[0.8-10.4]}\end{array}$ & $\begin{array}{c}8.3 \\
{[3.9-17]}\end{array}$ \\
\hline & Toubanding & 101 & $\begin{array}{c}48.3 \\
{[38.1-58.6]}\end{array}$ & $\begin{array}{c}42.5 \\
{[32.7-753]} \\
\end{array}$ & $\begin{array}{c}1.1 \\
{[0.2-6.2]} \\
\end{array}$ & $\begin{array}{c}8 \\
{[3.9-15.7]} \\
\end{array}$ & $\begin{array}{c}13.9 \\
{[8.4-21.9]}\end{array}$ \\
\hline \multirow{3}{*}{ An. funestus } & Daga Ndoup & 1 & 100 & 0 & 0 & 0 & 0 \\
\hline & Keur Samba Guèye & - & - & - & - & - & - \\
\hline & Toubanding & 27 & $\begin{array}{c}24 \\
{[11.5-43.4]}\end{array}$ & $\begin{array}{c}72 \\
{[52.4-85.7]}\end{array}$ & $\begin{array}{l}0 \\
-\end{array}$ & $\begin{array}{c}4 \\
{[0.7-19.5]}\end{array}$ & $\begin{array}{c}7.4 \\
{[2.1-23.4]}\end{array}$ \\
\hline
\end{tabular}

[ ]: $95 \%$ confidence interval.

Ndoup, 65.2\% in Keur Samba Guèye, and 48.3\% in Toubanding and there was no significant difference between the three villages $\left(\chi^{2}=6.2, \mathrm{df}=2\right.$, and $\left.P=0.05\right)$. Mixed blood meals were observed for An. gambiae in Daga Ndoup (8\%), Keur Samba, Guèye (8.3\%), and in Toubanding (13.9\%). Other sources of blood meal were from cattle (Bovine) and Equine for Daga Ndoup and Keur Samba Guèye and from Ovine for Toubanding.

The proportion of mixed blood meals was $7.4 \%$ in Toubanding for An. funestus. Overall, 24\% were from human source, $72 \%$ Bovine, and 4\% Equine (Table 2). In Daga Ndoup, only one An. funestus fed on human was collected.

3.4. Parity Rates. A total of 39 females An. gambiae s.l. were dissected for parity from Daga Ndoup, 51 from Keur Samba Guèye, and 206 from Toubanding and the results are presented in Table 3 . The parity rates were significantly different for An. gambiae between the three villages $\left(\chi^{2}=9.5\right.$, $\mathrm{df}=2$, and $P=0.009$ ). Parity rate was higher in Keur Samba Guèye, compared to the other two villages. Parity rate was $78 \%$ for An. funestus in Toubanding village. There is a significant difference with An. gambiae females collected in the same village $\left(\chi^{2}=8.6, \mathrm{df}=1\right.$, and $\left.P=0.003\right)$.

3.5. Circumsporozoite (CSP) and Entomological Inoculation Rates (EIR). CSP ELISA to detect $P$. falciparum circumsporozoite antigen was conducted on all 468 Anopheles specimens collected in the three villages. A confirmatory test was done on all specimens giving positive ELISA results. For the An. gambiae s.l. species collected in the 3 villages (Toubanding, Keur Samba Guèye, and Daga Ndoup), the sporozoite rates were, respectively, 2.50\% (CI 95\% = 1.15-5.35), 1.05\% (CI $95 \%=0.19-5.72$ ), and $1.72 \%$ (CI 95\% = 0.3-9.13). In the An. funestus samples collected in Toubanding, 3.23\% (CI 95\% = 0.89-11.03) were positive (Table 4 ). The differences were not statistically significant for An. gambiae s.l. circumsporozoite protein rates between the three villages $\left(\chi^{2}=0.7, \mathrm{df}=2\right.$, and $P=0.68)$.

The entomological inoculation rate (EIRs) for this area was estimated at 30 infective bites per person during the study period in Toubanding, 4 infective bites per person in Daga Ndoup and Keur Samba Guèye. In Daga Ndoup and Keur Samba Guèye, An. gambiae s.l. was mainly responsible for the transmission and it was concentrated in September, whilst in Toubanding both An. funestus and An. gambiae were responsible for transmission for 3 months of the season (August, September, and October).

\section{Discussion}

During this study, five out of 20 anopheline species described in Senegal [17] as well as the molecular forms of An. gambiae s.s. (M and S) were recorded. The predominant species within the Anopheles gambiae complex from the collections in this 
Table 3: Parity rates of An. gambiae and An. funestus in Daga Ndoup, Keur Samba Guèye, and Toubanding during the six surveys.

\begin{tabular}{lcccc}
\hline Species & Villages & Dissected & Parous & PR [95\% CI] \\
\hline \multirow{4}{*}{ An. gambiae } & Daga Ndoup & 39 & 15 & $38.5[24.9-54.1]$ \\
& Keur Samba Guèye & 51 & 36 & $70.6[57-81.3]$ \\
\hline \multirow{3}{*}{ An. funestus } & Toubanding & 156 & 83 & $53.2[45.4-60.9]$ \\
& Daga Ndoup & - & - & - \\
& Keur Samba Guèye & - & - & 78 \\
\end{tabular}

PR: parity rate in percentage.

[ ]: $95 \%$ confidence interval.

TABle 4: Mean infection rate calculated by ELISA for P. falciparum for An. gambiae, An. funestus, and An. pharoensis in Daga Ndoup, Keur Samba Guèye, and Toubanding.

\begin{tabular}{lcccc}
\hline Villages & Species & HBR $(\mathrm{b} / \mathrm{p} / \mathrm{n})$ & CSPR $(\%)$ & EIR $(\mathrm{Ib} / \mathrm{p} / \mathrm{n})$ \\
\hline \multirow{3}{*}{ Daga Ndoup } & An. funestus & 0.02 & 0 & 0 \\
& An. gambiae & 1.21 & $1.72(0.3-9.13)$ & 0 \\
\hline \multirow{3}{*}{ Keur Samba Guaroensis } & 0 & 0 & $0.02(0.004-0.11)$ \\
& An. funestus & 0.06 & $1.05(0.19-5.72)$ & 0 \\
\hline \multirow{3}{*}{ Toubanding } & An. gambiae & 1.98 & 0 & $0.02(0.004-0.11)$ \\
& An. pharoensis & 0.02 & $3.23(0.89-11.03)$ & 0 \\
& An. funestus & 1.29 & $2.50(1.15-5.35)$ & $0.04(0.01-0.14)$ \\
& An. gambiae & 5 & 0 & $0.13(0.006-0.27)$ \\
\hline
\end{tabular}

HBR: human-biting rate.

CSPR: circumsporozoite rate.

EIR: entomological inoculation rate.

$\mathrm{Ib} / \mathrm{p} / \mathrm{n}$ : infective bites per person per night.

( ): $95 \%$ confidence interval.

area is An. arabiensis. This observation contrasts with the recent records in the area that show that An. gambiae s.s. represents about $80 \%$ of the species of An. gambiae complex collected [6]. Such differences could be due to differences in microgeographic ecological characteristics within the study area.

The highest densities were observed in Toubanding village only. This observation again could be related to the ecological differences between our study villages. This discrepancy is sustained by the fact that other vector species were present. In Daga Ndoup and Keur Samba Guèye, mosquito-breeding sites are rain dependent with pools and puddles indiscriminately scattered around the village for short periods only. Toubanding, on the other hand, is located near a small stream that permits the development of anopheline breeding sites for longer periods. In Dielmo village situated $1.5 \mathrm{~km}$ apart, this stream permits the persistence of anopheline breeding sites all year round [18]. This can explain the presence of An. funestus and An. gambiae throughout the duration of the study period. The populations' dynamics of these species have similar characteristics to what is usually observed in Sahelian zones $[12,19]$. Fluctuations in populations' densities of An. gambiae are related to rainfall pattern as is generally found in the other bioclimatic areas of Senegal [20-22].

Despite the limited distances between the selected villages, there was an 8 -fold variation between Toubanding compared to the other two villages in terms of transmission potential. This is probably mainly due to the heterogeneity on anopheline vectors as observed. Such an observation was already assessed between the two most studied villages in the study area, namely, Dielmo and Ndiop [10, 11]. The transmission was seasonal, occurring for only one-to-three months of the year depending on the village locations. In Daga Ndoup and Keur Samba Guèye, malaria transmission is observed only in September, whilst in Toubanding, transmission occurs from August to October with a peak period observed in September. Daga Ndoup and Keur Samba Guèye villages have temporal breeding sites and Toubanding has what is a more permanent breeding ground for vectors throughout the year. However, it is important to note that despite the existence of this stream in Toubanding, malaria transmission does not proceed beyond October. Even if there is a transmission after October, it will be at low levels below the sensitivity of the method used to detect transmission. This is contrary to the existence of perennial transmission in the village of Dielmo thanks to the presence of the Nema river that permits and supports the persistence of anopheline breeding sites all year round [6].

In Toubanding village, which showed the highest densities of An. gambiae populations, compared with Daga Ndoup and Keur Samba Guèye, the anthropophilic rate is very low. A similar scenario was observed for the same species in Burkina Faso [23], in Burundi [24], and recently in 
An. funestus populations from northern Senegal [22]. Given the comparable levels of infestations observed, the highest transmission estimated in Toubanding in the case of $A n$. gambiae is probably due to higher densities observed for this vector species.

It is noteworthy to mention the main reasons for low levels of transmission in Keur Samba Guèye and Daga Ndoup, which has similar transmission levels considering the fact that local divergences are obvious with the presence of the Nema river near Toubanding village. The results obtained for Daga Ndoup and Keur Samba Guèye could be extrapolated to all other villages in the area with rain-dependent breeding sites. However, one should be cautious of the fact that other local ecological features or interannual variations in rainfall could lead to differences between villages as was already observed elsewhere $[10,11,25,26]$.

Taking into account our collated entomological results and the specific objectives of the study as set out initially, epidemiological field trials can be conducted in this area. In this process, the timeline should target the peak transmission period, which is September, especially for vaccine in order to achieve peak antibody response or peak infection rate with increasing transmission.

\section{Conflict of Interests}

The authors declare that they have no competing interests.

\section{Acknowledgments}

The authors gratefully acknowledge the medical authorities of Toubacouta sanitary district, Mamadou Sonko for his technical assistance and Musa Jawara and Richard Paul for help in English translation. Financial funding was provided by the European and Developing Countries Clinical trials Partnership (EDCTP) and the Institut Pasteur de Dakar.

\section{References}

[1] WHO, World Malaria Report 2011, WHO Press, Geneva, Switzerland, 2011.

[2] S. J. Ceesay, C. Casals-Pascual, D. C. Nwakanma et al., "Continued decline of malaria in The Gambia with implications for elimination," PLoS ONE, vol. 5, no. 8, Article ID e12242, 2010.

[3] B. M. Greenwood, D. A. Fidock, D. E. Kyle et al., "Malaria: progress, perils, and prospects for eradication," Journal of Clinical Investigation, vol. 118, no. 4, pp. 1266-1276, 2008.

[4] J. Tumwiine, J. Y. T. Mugisha, and L. S. Luboobi, "A mathematical model for the dynamics of malaria in a human host and mosquito vector with temporary immunity," Applied Mathematics and Computation, vol. 189, no. 2, pp. 1953-1965, 2007.

[5] A. C. Ghani, C. J. Sutherland, E. M. Riley et al., "Loss of population levels of immunity to malaria as a result of exposurereducing interventions: consequences for interpretation of disease trends," PLoS ONE, vol. 4, no. 2, Article ID e4383, 2009.

[6] J. F. Trape, A. Tall, N. Diagne et al., "Malaria morbidity and pyrethroid resistance after the introduction of insecticidetreated bednets and artemisinin-based combination therapies: a longitudinal study," Lancet Infectious Disease, vol. 11, no. 12, pp. 925-932, 2011.

[7] M. M. Riehle, W. M. Guelbeogo, A. Gneme et al., "A cryptic subgroup of Anopheles gambiae is highly susceptible to human malaria parasites," Science, vol. 331, no. 6017, pp. 596-598, 2011.

[8] T. Smith, J. D. Charlwood, W. Takken, M. Tanner, and D. J. Spiegelhalter, "Mapping the densities of malaria vectors within a single village," Acta Tropica, vol. 59, no. 1, pp. 1-18, 1995.

[9] D. Fontenille, L. Lochouarn, N. Diagne et al., "High annual and seasonal variations in malaria transmission by anophelines and vector species composition in Dielmo, a holoendemic area in Senegal," American Journal of Tropical Medicine and Hygiene, vol. 56, no. 3, pp. 247-253, 1997.

[10] P. D. McElroy, J. C. Beier, C. N. Oster et al., "Predicting outcome in malaria: correlation between rate of exposure to infected mosquitoes and level of Plasmodium falciparum parasitemia," American Journal of Tropical Medicine and Hygiene, vol. 51, no. 5, pp. 523-532, 1994.

[11] D. Fontenille, L. Lochouarn, M. Diatta et al., "Four years' entomological study of the transmission of seasonal malaria in Senegal and the bionomics of Anopheles gambiae and $v$," Transactions of the Royal Society of Tropical Medicine and Hygiene, vol. 91, no. 6, pp. 647-652, 1997.

[12] M. T. Gillies and B. De Meillon, "The Anophelinae of Africa south of the Sahara (Ethiopian zoogeographical region)," Publications of the South African Institute of Medical Research, vol. 54, pp. 1-343, 1968.

[13] T. S. Detinova, Age Grouping Methods in Diptera of Medical Importance with Special Reference to Some VecTors of Malaria, WHO Monograph, Geneva, Switzerland, 1962.

[14] J. C. Beier, P. V. Perkins, R. A. Wirtz et al., "Bloodmeal identification by direct enzyme-linked immunosorbent assay (ELISA), tested on Anopheles (Diptera: Culicidae) in Kenya," Journal of Medical Entomology, vol. 25, no. 1, pp. 9-16, 1988.

[15] R. A. Wirtz, F. Zavala, and Y. Charoenvit, "Comparative testing of monoclonal antibodies against Plasmodium falciparum sporozoites for ELISA development," Bulletin of the World Health Organization, vol. 65, no. 1, pp. 39-45, 1987.

[16] C. Fanello, V. Petrarca, A. della Torre et al., “The pyrethroid knock-down resistance gene in the Anopheles gambiae complex in Mali and further indication of incipient speciation within An. gambiae s.s." Insect Molecular Biology, vol. 12, no. 3, pp. 241-245, 2003.

[17] N. Diagne, D. Fontenille, L. Konate et al., "Les anophèles du Sénégal: liste commentée et illustrée," Bulletin De La Société De Pathologie Exotique, vol. 87, pp. 267-277, 1994.

[18] J. F. Trape, C. Rogier, L. Konate et al., “The Dielmo project: a longitudinal study of natural malaria infection and the mechanisms of protective immunity in a community living in a holoendemic area of Senegal," American Journal of Tropical Medicine and Hygiene, vol. 51, no. 2, pp. 123-137, 1994.

[19] J. Brengues, J. Brunhes, and J. P. Hervy, "La filariose de Bancroft en Afrique, à Madagascar et dans les Iles voisines," Etudes Médicales, vol. 1, pp. 1-85, 1979.

[20] V. Robert, H. Dieng, L. Lochouarn et al., "La transmission du paludisme dans la zone de Niakhar, Senegal," Tropical Medicine and International Health, vol. 3, no. 8, pp. 667-677, 1998.

[21] I. Dia, T. Diop, I. Rakotoarivony, P. Kengne, and D. Fontenille, "Bionomics of Anopheles gambiae Giles, A. arabiensis Patton, A. funestus Giles and A. nili (Theobald) and transmission of Plasmodium falciparum in a Sudano- Guinean zone 
(Ngari, Senegal)," Journal of Medical Entomology, vol. 40, no. 3, pp. 279-283, 2003.

[22] I. Dia, L. Konate, B. Samb et al., "Bionomics of malaria vectors and relationship with malaria transmission and epidemiology in three physiographic zones in the Senegal River Basin," Acta Tropica, vol. 105, no. 2, pp. 145-153, 2008.

[23] V. Robert, V. Ouedraogo, and P. Carnevale, "La transmission $\mathrm{du}$ paludisme humain dans un village au centre de la rizière de la vallée du Kou, Burkina Faso," Editions. ORSTOM, Collection Études Et Thèses, pp. 5-12, 1991.

[24] M. H. Coosemans, "Comparaison de l'endémie malarienne dans une zone de riziculture et dans une zone de culture de coton dans la plaine de Rusizi, Burundi," Annales De La Société Belge De MéDecine Tropicale, vol. 65, pp. 187-200, 1985.

[25] J. J. Lemasson, D. Fontenille, L. Lochouarn et al., "Comparison of behavior and vector Efficiency of A. gambiae and A. arabiensis (Diptera: Culicidae) in Barkedji, a Sahelian Area of Senegal," Journal of Medical Entomology, vol. 34, no. 4, pp. 396-403, 1997.

[26] J. C. Beier, P. V. Perkins, F. K. Onyango et al., "Characterization of malaria transmission by Anopheles (Diptera: Culicidae) in western Kenya in preparation for malaria vaccine trials," Journal of Medical Entomology, vol. 27, no. 4, pp. 570-577, 1990. 


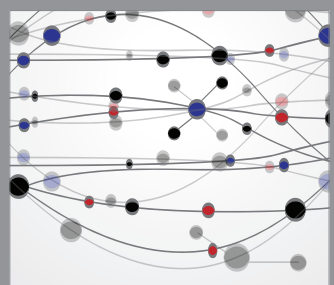

The Scientific World Journal
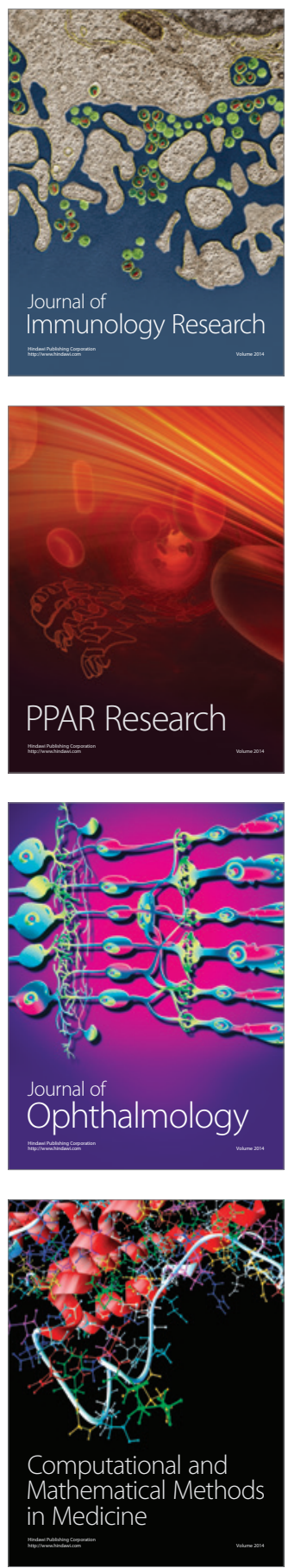

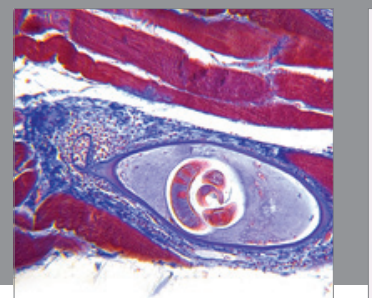

Gastroenterology

Research and Practice
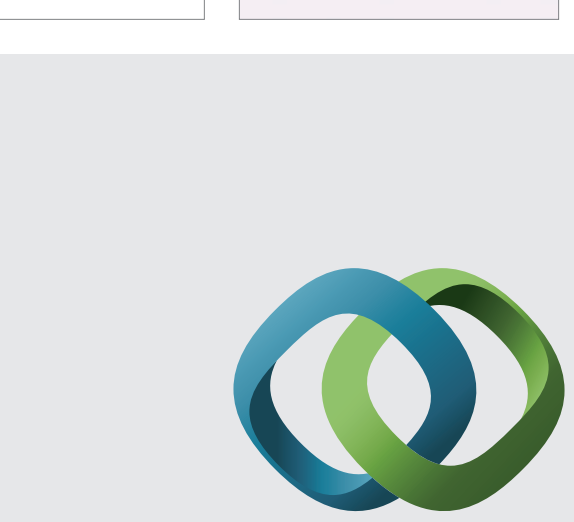

\section{Hindawi}

Submit your manuscripts at

http://www.hindawi.com
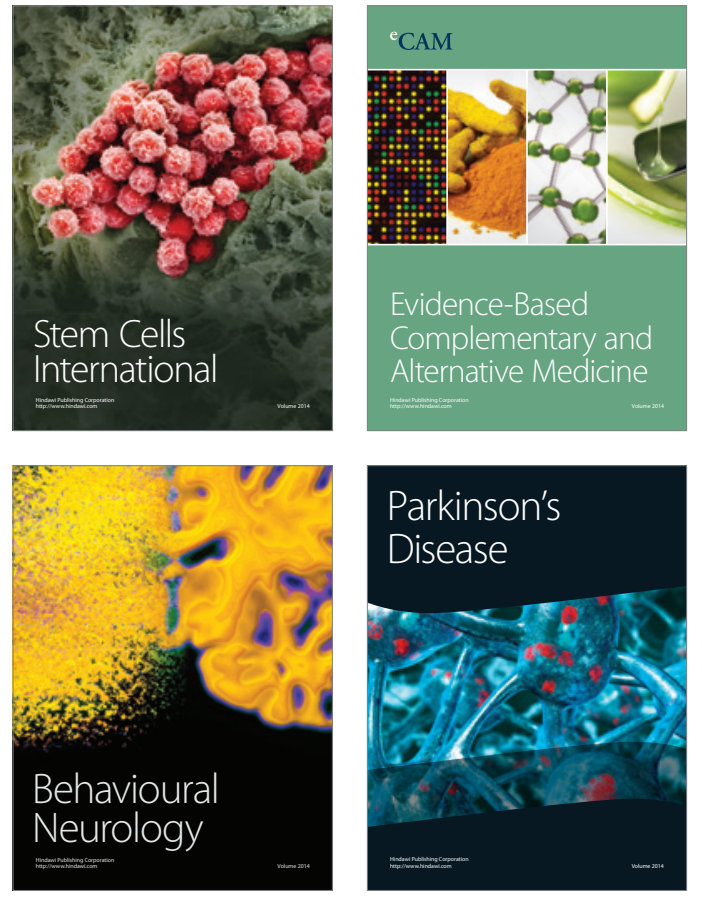
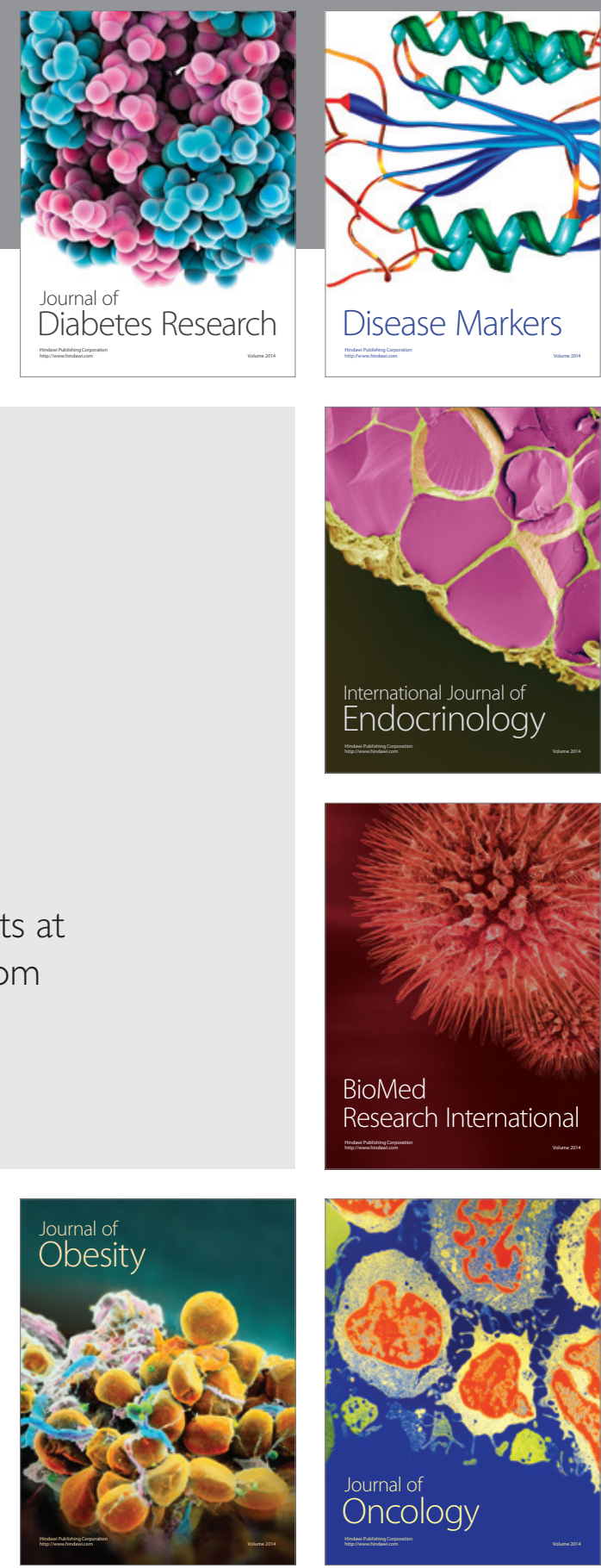

Disease Markers
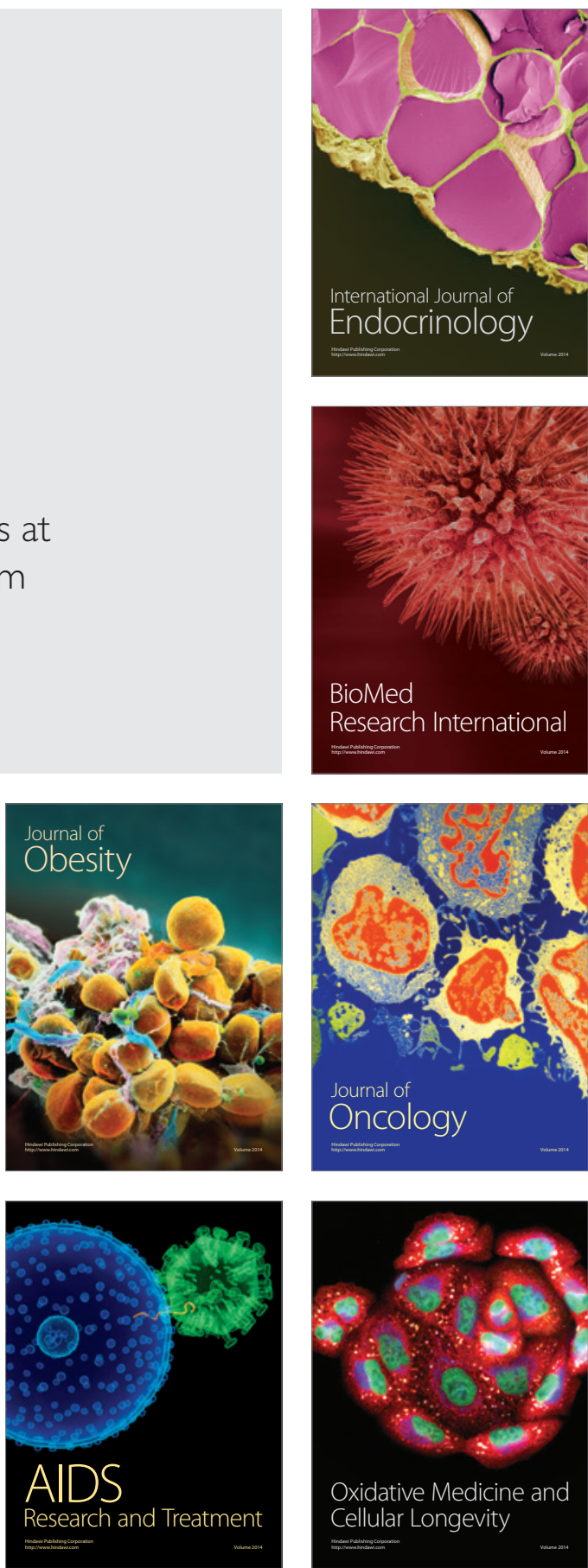